\title{
Letter and word code interactions elicited by normally displayed words
}

\author{
JANICE A. LAWRY \\ University of California, Los Angeles, California 90024 \\ and \\ DAVID LaBERGE \\ University of Minnesota, Minneapolis, Minnesota 55455
}

\begin{abstract}
The dependence of visual word recognition on letter processing was investigated by measuring the effect of a cue word on subsequent target word processing for various degrees of cue/ target similarity. Using a simultaneous matching task (Experiments 1 and 2), modest facilitation was found for identical cue/target items only, whereas items that differed by a single letter led to substantial interference. Targets that shared internal or external letters with cues yielded latencies comparable to those for neutral or different cue conditions. The identical facilitation and high-similarity interference was also found in a lexical decision task under normal display conditions (Experiment 3). However, when direct letter processing was measured using spatially transformed targets (Experiment 4), large facilitatory effects were found for similar as well as for identical cue/target conditions. Although both letter and word codes appear to be activated by normally displayed words, such word code activity may not routinely depend upon letter code outputs.
\end{abstract}

Many models of word perception (Estes, 1977; LaBerge \& Samuels, 1974; Massaro, 1975; McClelland, 1979) propose that word codes are activated by means of constituent letter codes. For these models, the link from letter to word codes is generally assumed to be direct or indirect by means of intermediate spellingpattern codes. The flow of activation may proceed in discrete steps, with letter codes reaching full activation before transmitting their output to the word code level. Alternatively, McClelland (1979) has proposed that the flow of activation from one level to the next is continuous and does not depend upon prior recognition events at lower levels. Consistent with this "cascade" assumption, sufficient activation may converge on the word code from letter or spelling pattern sources, enabling it to reach recognition criterion before any given letter or spelling pattern code reaches its particular recognition threshold.

In all of these variations of the letter-to-word hierarchy model, the picture of word code activation

This research was supported in part by Grant BNS-7904677 to David LaBerge from the National Science Foundation and by Grants HD-00098 and HD-01136 to the Center for Research in Human Learning, University of Minnesota, from the National Institute of Child Health and Human Development. This research was conducted while J.A.L. was an associate of the Center for Research in Human Learning, and Experiment 4 is based upon a thesis submitted by her in partial fulfillment of the requirements for a doctoral degree at the University of Minnesota. Reprint requests should be addressed to Janice A. Lawry, Department of Psychology, 405 Hilgard Avenue, UCLA, Los Angeles, California 90024. is one of a bottom-up, stimulus-driven process in which letter codes at lower levels of the perceptual system continue to feed their outputs into higher levels of codes until a word code reaches its recognition threshold. The purpose of the present experiments is to measure this dependence of word code activation on prior letter code activation.

According to the letter-to-word processing viewpoint, any display that activates a word code must necessarily have activated the constituent letter codes as well, whether or not such activation is sufficient to exceed the recognition thresholds of the letter codes. It seems reasonable, therefore, to expect that words that share letters should facilitate each other via the shared letter code participation in their recognition. For example, if a person were to see the word store just prior to the word stone, then the word stone should be processed faster than if the word laugh had preceded stone. Specifically, if stone is presented while the four letter codes it shares with store are still partially activated, then the code for stone should reach its recognition threshold more quickly than normal.

In an attempt to assess the effects of prior activation of particular letters on subsequent word processing, we considered that letters in certain positions might produce greater facilitation than letters in other positions. Studies of positional effects of letters in word processing have generally found that outside letters carry special weight. Using a Stroop-type task in which subjects named pictured objects with in- 
scribed labels, Rayner and Posnansky (1978) found that a label containing only the correct first and last letters facilitated picture-naming relative to control conditions whose labels had no correct letters. Unfortunately, a condition to assess the contribution of inside letters was not included in this study. Eriksen and Eriksen (1974), however, have explored all letter positions in a word naming task. Using four-letter words, they found that the first letter was more important than any other in terms of identification. In consideration of such letter position effects in word processing, the present design included conditions in which the contributions of letters in various positions could also be assessed.

The role of previously presented words (cues) on subsequently presented words (targets) was investigated here using the prior activation methodology developed by Posner and Snyder (1975). In a letter matching task, they found that target letter pairs (AA) were matched $31 \mathrm{msec}$ faster when preceded by an identical letter cue (A) than when preceded by either a neutral plus sign $(+)$ or a different letter (B). There was no difference in the matching latencies of the neutral and different cue conditions. This small but reliable facilitatory effect of the identical cue is thought to measure the amount of residual activation in those common pathways used to process the cue and target letters. This effect is said to occur automatically without the person's awareness in cases in which there is relatively low predictability of target identity (Posner, 1978).

When there is high target predictability, a different pattern emerges. Specifically, Posner and Snyder (1975) found that if there were $80 \%$ identical cue/ target trials, this led to $85-\mathrm{msec}$ facilitation for the identical targets. With attention focused on the "expected" target letter code, a high degree of activation can be maintained and a greater processing benefit obtained. However, such a strategy produces some cost when a letter is different from that expected. In this case, latencies are $36 \mathrm{msec}$ slower than in the neutral condition. This added time is thought to be necessary for the attentional switching between the expected code and the newly activated code (LaBerge, 1973).

In the present experiments, we hoped to measure the effects of prior activation of the letter code networks thought to produce word code activation under conditions that did not encourage the use of expectancy-based strategies or involve attentional switching. In our evaluation, the effects of letters that the cue and target have in common, as well as the effects of different letters, were measured against a neutral cue condition. The latter comparison provided a check for possible strategy effects.

\section{EXPERIMENTS 1 AND 2}

Experiments 1 and 2 employed a matching paradigm in which different degrees of cue/target similarity were explored. In the specific simultaneous matching task adopted here, two pairs of items, a cue pair and target pair, were presented on each trial. The task involved making a same/different judgment on each pair. No comparison across the cue and target items was required, and subjects were not informed of the possible similarity relationships between the cue and target words.

At the start of each trial, two cue items (either a pair of words or a pair of plus and minus signs) were presented side by side. Subjects were told to compare the items for physical identity. If the cue items matched, they were then to prepare to see a second pair of items (targets). If the cue items did not match, they were told to simply ignore the target pair and to wait for the next trial to begin. This first match served to insure that the subject fully activated the pathways necessary for processing the cue item. On trials with matching cue items, subjects indicated whether the target words matched by pressing one button and whether they mismatched by pressing another button. Examples of the cue and target items for the various cue/target conditions and trial types are provided in Table 1.

Table 1

Examples of Cue-Target Items Used in Experiments 1 and 2

\begin{tabular}{|c|c|c|c|c|c|c|}
\hline & \multicolumn{6}{|c|}{ Cue-Target Condition } \\
\hline & Identical & Hi-Similar & OL-Similar* & IL-Similar $\dagger$ & Different & Neutral \\
\hline & \multicolumn{6}{|c|}{ Matching Trials } \\
\hline \multirow[t]{2}{*}{$\begin{array}{l}\text { Cue Pair } \\
\text { Target Pair }\end{array}$} & $\begin{array}{l}\text { sack sack } \\
\text { sack sack }\end{array}$ & $\begin{array}{l}\text { wave wave } \\
\text { wove wove }\end{array}$ & $\begin{array}{l}\text { bold bold } \\
\text { bend bend }\end{array}$ & $\begin{array}{l}\text { gear gear } \\
\text { leak leak }\end{array}$ & $\begin{array}{l}\text { ring ring } \\
\text { fowl fowl }\end{array}$ & $\begin{array}{l}+-+-+-+- \\
\text { mint mint }\end{array}$ \\
\hline & \multicolumn{6}{|c|}{ Mismatch Trials } \\
\hline \multirow[t]{2}{*}{$\begin{array}{l}\text { Cue Pair } \\
\text { Target Pair }\end{array}$} & $\begin{array}{l}\text { bank bank } \\
\text { bank bask }\end{array}$ & $\begin{array}{l}\text { dish dish } \\
\text { dash hash }\end{array}$ & $\begin{array}{l}\text { chew chew } \\
\text { crow crew }\end{array}$ & $\begin{array}{l}\text { lean lean } \\
\text { meat meet }\end{array}$ & $\begin{array}{l}\text { pity pity } \\
\text { beam seam }\end{array}$ & $\begin{array}{l}++-++-- \\
\text { fond pond }\end{array}$ \\
\hline & \multicolumn{6}{|c|}{ Catch Trials } \\
\hline $\begin{array}{l}\text { Cue Pair } \\
\text { Target Pair }\end{array}$ & $\begin{array}{l}\text { free tree } \\
\text { free free }\end{array}$ & $\begin{array}{l}\text { hunt hunk } \\
\text { hurt hurt }\end{array}$ & $\begin{array}{l}\text { take fake } \\
\text { tore tore }\end{array}$ & $\begin{array}{l}\text { site cite } \\
\text { mitt mitt }\end{array}$ & $\begin{array}{l}\text { wages pages } \\
\text { peach peach }\end{array}$ & $\begin{array}{l}++-++++-+- \\
\text { loose loose }\end{array}$ \\
\hline
\end{tabular}

Note-See Method section for complete description of trial types, stimulus materials, and response requirements.

*Experiment 1 only. tExperiment 2 only. 
The effect of the particular letter and/or word code activation initiated by the cue display was measured by latency to match the target words. By systematically varying the physical similarity between the cue and target words, we hoped to determine the degree to which prior activation of relevant letter codes facilitated word perception. In general, greater physical similarity between cue and target words should result in greater overlap between processing pathways of the target and those previously activated by the cue. Based upon our interpretation of the letter-to-word model, such overlap ought to produce response facilitation relative to the control conditions in which there is no overlap between the letter code networks of the cue and target words. Furthermore, the greater the estimated overlap is, the greater the expected facilitation.

\section{Method}

Subjects. All subjects were native English-speaking college undergraduates currently enrolled in an introductory psychology course at the University of Minnesota, where they received two extra credit points for their participation. Each subject participated in only one experiment. There were 48 subjects tested in Experiment 1 and 32 subjects tested in Experiment 2.

Apparatus. All stimuli were presented on $38-\mathrm{cm}$ diagonal television screens driven by a Tektronix 4501 scan converter. Data General NOVA computers controlled all aspects of stimulus presentation, timing, and response collection. Words were displayed in black lowercase letters on a light background. Each letter was constructed within a 7 by 15 dot matrix that measured approximately $9 \times 19 \mathrm{~mm}$ on the screen and subtended $25 \times 38 \mathrm{~min}$ of visual angle. The space between the letters was approximately $2.6 \mathrm{~mm}$.

Subjects were tested individually or in pairs while seated in individual booths in an experimental room. A television screen was mounted at eye level and was positioned $125 \mathrm{~cm}$ from the edge of the table in the booth in which the subject was seated. In front of each subject was a response panel containing two $25-\mathrm{cm}$-diam response buttons. Subjects controlled the onset of each block of trials by pressing one of the buttons in response to the prompt "begin" on the screen.

Stimulus materials and trial types. Both experiments included the following cue/target relationships: (1) identical-the cue and target words were physically identical; (2) hi-similar - the cue and target had all but one internal letter the same; (3) different-the cue had no letters in common with the target relative to position; and (4) neutral-the cue was composed of a string of plus and minus signs of the same length as the target word. In Experiment 1, cue/ target words were also included that had the same outside letters but different inside letters (OL-similar). Conversely, cue/target words were included in Experiment 2 that had the same inside letters but different outside letters (IL-similar). Table 1 provides examples of cue/target stimuli for each trial type.

The reason for not including all of the similarity conditions of interest in one large experiment was partly because of design limitations imposed by item selection criteria, and also because it was feared that a preponderance of similar cue/target relationships might encourage subjects to expect targets that share letters with the cue. As a further precaution against the development of such expectancies, additional different cue/target items were added to each stimulus list so that the combined number of identical and similar items never exceeded $50 \%$ of the trials cued by words.

Care was taken to control for general familiarity of the cue and target words. This was accomplished by using the standard frequency index (SFI) values of Carroll, Davis, and Richman (1971).
The average SFI values were equated for Cue/Target Condition by Word Length subsets within each experimental test set. These values ranged from 52.0 to 53.5 , while SFI values for individual target words varied from 42.0 to 63.2 .

Each experiment contained three types of trials: matching, mismatch, and catch trials. The cue/target conditions tested in each experiment were represented in all three trial types. Examples are provided in Table 1.

Matching trials were those in which the two cue words matched and the two target words also matched. Items for these trials were generated by selecting cue and target words that bore one of the cue/target relationships to be explored (i.e., identical, hi-similar, etc.).

Mismatch trials were those in which the cue word pair matched but the target word pair did not. Items for these trials were generated by selecting word triplets such that the cue word and first member of the target pair had one of the cue/target relationships to be tested. The second member of the target pair differed from the first by a single letter. For half of the items, the discrepant letter was in an outside position, and for the other half, it was internally positioned.

Catch trials were those in which the cue word pair did not match and the target pair did match. Items were generated by choosing word triplets containing two cue words and a target word. The first cue word and target bore one of the cue/target relationships to be tested. Cue words "mismatched" in the same manner as described for mismatch target pairs. In the neutral condition, the pair of plus and minus signs also differed by a single element.

Design. In Experiment 1, a "rotated targets" design was used. In each set of matching items, the same target words were paired with new cue items such that each target word appeared once in each cue/target condition across stimulus sets. Each set of 84 matching items was then added to a single set of $\mathbf{4 2}$ mismatch and 12 catch trial materials to make a complete test set. There were four matching and two mismatch items at each of three word lengths (four, five, and six letters) in each cue target condition. Subjects were assigned randomly to one of the test set variations so that each person saw a given target word only once during the experiment. The overall design involved two main experimental factors, cue target condition and word length. Matching items were nested within length and were crossed with condition. Mismatch items were nested within Condition by Length cells.

Due to the difficulty in generating IL-similar items, a "fixed targets" design was used in Experiment 2 with four- and fiveletter words only. Here, target words appeared in only one test set and in only one condition. Matching items were therefore nested within Test Set by Condition by Length cells. There were two test sets, each with 96 unique matching items, plus the same set of 48 mismatch and 12 catch items. There were eight matching and four mismatch items at each word length.

For purposes of analysis, matching and mismatch data were treated separately using min $F^{\prime}$ statistics based on ANOVAs, with subjects and items as random variables (Clark, 1973). All other factors were treated as fixed.

Procedure. Each experimental session consisted of presenting the instructions and a brief set of practice trials followed by the test set. Subjects were given a $15-\mathrm{sec}$ rest between trial blocks of the test set. Both practice and test sets contained the same cue/ target conditions, but they differed in terms of the percentages of the three trial types. The practice sets contained 50\% matching, $25 \%$ mismatch, and $25 \%$ catch trials, whereas the test sets contained approximately $60 \%$ matching, $30 \%$ mismatch, and $10 \%$ catch trials. It was hoped that the greater percentage of catch trials during the practice would encourage subjects to establish a habit of always processing the cue words fully.

At the start of each trial, two cue items (either a pair of words or a pair of plus and minus sign patterns) were presented in the upper left quadrant of the screen. These items were displayed side by side and were centered within a 14-character display window. 
The items were separated by two to four character spaces depending upon word length. After 1,500 $\mathrm{msec}$, the cue items were erased, and the screen remained blank for $500 \mathrm{msec}$; then two target words appeared side by side in the lower right quadrant of the screen. These items remained on until the subject responded or for a maximum of $1,250 \mathrm{msec}$. Subjects were allowed up to $1,500 \mathrm{msec}$ to respond; response latencies exceeding $1,500 \mathrm{msec}$ were regarded as "misses" and were not included in the data. The intertrial interval (ITI) was 1,500 msec, during which time the screen remained blank.

Instructions described the experiment as a study in word processing, the purpose of which was to investigate how mature readers perceive words. Subjects were told that each trial would begin with the presentation of two words or strings of plus and minus signs (cue items) in the upper part of their screens. If these items did not physically match (catch trials), the subjects were told to ignore the rest of the trial and to wait for the next pair of items to appear in that position. If, however, the cue items did match, they were instructed to shift their attention to the lower right part of the screen, where a second pair of words (target items) would soon appear. If these two words were physically identical (matching trials), they were told to press the right button on their response panels. If the target words did not match (mismatch trials), they were told to press the left button on their response panels. Subjects were shown cards illustrating the various trial types. Nowhere in the instructions were subjects informed of the possible relationships between the cue and target words.

\section{Results}

Matching data (right-hand responses). The subject and items ANOVAs used to generate $\min F^{\prime}$ values included cue/target condition and word length factors. Test set was eliminated from the final analyses when preliminary findings indicated that there were no reliable differences across stimulus lists and set did not interact with any of the other factors.

Response latencies varied greatly as a function of cue/target condition in both Experiment 1 [min $\left.F^{\prime}(5,575)=10.78, \mathrm{p}<.001\right]$ and Experiment 2 [min $\left.F^{\prime}(4,249)=10.52, p<.001\right]$. As illustrated in Figures

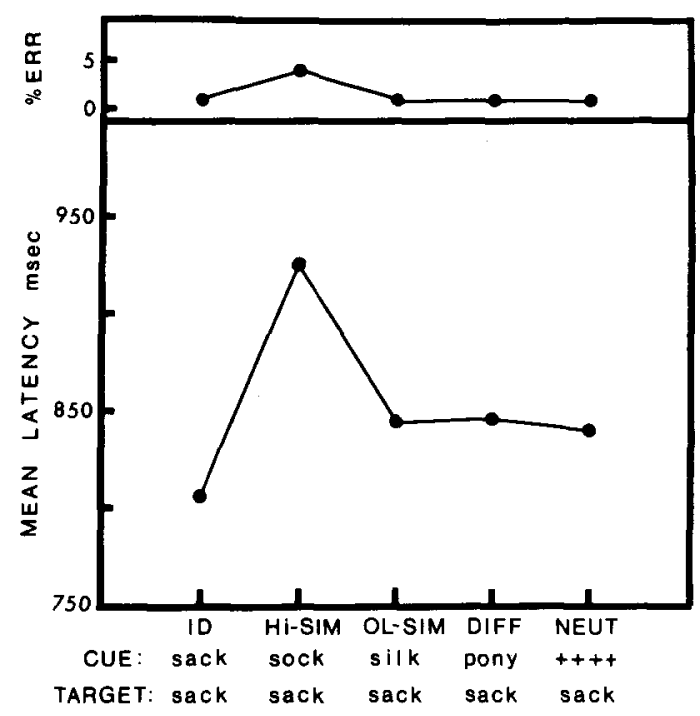

Figure 1. Mean response latency and percent errors for matching pairs of simultaneously presented words as a function of their visual similarity to the cue words in Experiment 1.

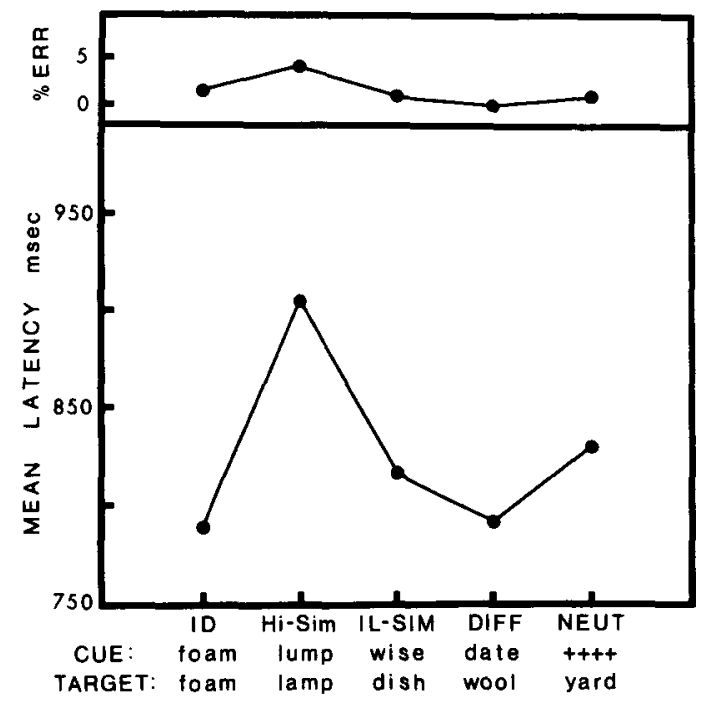

Figure 2. Mean response latency and percent errors for matching pairs of simultaneously presented words as a function of their visual similarity to the cue words in Experiment 2.

1 and 2 , the pattern of condition effects was similar across the two experiments. In both cases, the identical condition produced the shortest response times, while the hi-similar condition produced the longest response times.

Planned comparisons revealed no evidence for interference in the different condition relative to the neutral cue/target condition. In the first experiment, the difference between the latencies of the two control conditions was negligible $(6 \mathrm{msec})$, and in the second experiment, the different condition was actually slightly faster than the neutral condition [ $t(249)$ $=2.77, p<.01]$. Although modest, the magnitude of the identical facilitation effect proved to be reliable relative to the combined neutral and different controls in Experiment $1[t(575)=3.83, p<.001]$ and the neutral condition in Experiment $2[\mathrm{t}(249)=2.98$, $\mathrm{p}<.01]$. The interference of the hi-similar condition was also found to be reliable relative to the combined controls in both Experiment $1[t(575)=-8.16, p<$ .001 and Experiment $2[t(249)=-7.66, p<.001]$. In contrast with the effects of hi-similarity, the OLsimilar and IL-similar condition latencies did not differ reliably from either the different or neutral control latencies.

Consistent with other word matching studies (Bruder, 1978; Eichelman, 1970), word length was also found to be a significant determinant of response latencies in Experiment 1 [min $F^{\prime}(2,113)=$ $13.30, \mathrm{p}<.001]$ and in Experiment 2 [min $\mathrm{F}^{\prime}(1,150)$ $=22.84, p<.001]$. A linear regression analysis indicated that response latencies increased at an approximate rate of $45 \mathrm{msec}$ per letter in Experiment 1. In Experiment 2, there was a 59-msec increase in latencies from four- to five-letter words. The lack of any 
Condition by Length interaction suggests that word length effects were not significantly modified by any cue/target condition.

As illustrated at the top of Figures 1 and 2, the overall error rate was low (approximately 3\%). A slightly higher percentage of errors occurred in the hi-similar conditions, and this deviation was sufficient in Experiment 2 to produce a reliable main effect of condition [min $\left.F^{\prime}(4,241)=3.32, p<.05\right]$. No other reliable effects on error rates were found.

Mismatch data (left-hand responses). Neither condition nor word length was found to produce reliable differences in response latencies or error rates, and there was no reliable interaction of these factors. This was expected, since mismatch latencies seem to be influenced more by the location and number of differences between the items to be compared (e.g., Eichelman, 1970). Overall, mismatch latencies were approximately $90 \mathrm{msec}$ longer than the matching latencies, and the error rates were also somewhat higher (7\% and 4\% in Experiments 1 and 2, respectively).

\section{Discussion}

Prior presentation of a cue word facilitated processing of a target word only when the two words were identical. In marked contrast was the finding that a cue word that shared all but one letter with the target led to substantial response interference. Furthermore, lesser degrees of similarity between the cue and target, as in the shared external and shared internal letter conditions, produced neither interference nor facilitation.

These results do not appear to measure the contribution of prior activation of shared letter networks. How, then, can they be interpreted? One explanation requires the additional analysis of word code interactions. In the hi-similar condition, the word code corresponding to the cue is expected to have some residual activation at the time of target presentation. According to a letter-word model, it should receive further activation as the relevant letters of the target are processed. A consequence of this may be that, for a time, the cue and target word codes are both activated to a fairly high degree. Additional time may then be required until the activation of the target sufficiently exceeds that of the cue permitting correct recognition to take place. In simpler terms, the system is receiving mixed signals at the word code level, and the resolution of the multiple activation requires additional processing time.

Including word code interactions does not easily explain, however, why there is a complete lack of interference and facilitation in the lesser similarity conditions. One could argue that two- or three-letter codes in common are inadequate to produce substantial word code interactions, but, then, why is there no emergence of letter-mediated facilitation? As a final retreat, it could be argued that there is some inter- ference at the word code level as well as some facilitation at the letter code level and that these two tend to cancel out one another. Although logically possible, this explanation is unsatisfactory, particularly in view of the complete lack of Condition by Length interactions in the two experiments. If there are varying degrees of facilitation and interference depending upon the relative number of shared letters, then it seems reasonable to expect that sharing two of six possible letters ought to produce a pattern different from that which sharing two of four letters produces. In fact, there were no reliable effects or emerging trends across word length in any of the cue/target conditions.

By staying within our original conception of the task, our explanations have become quite strained. Perhaps our focus on letter code networks has been inappropriate. The effects here might be explained solely as a function of word code interactions without any direct or indirect involvement of letter codes. This new focus on word codes seems supported by the very modest facilitation found for identical cue/ target words. The magnitude of the effects obtained here $(34 \mathrm{msec}$ in Experiment 1 and $42 \mathrm{msec}$ in Experiment 2) is comparable to that reported by Posner and Snyder (1975) for the prior activation of a single letter code ( $31 \mathrm{msec})$. If prior activation of a relevant word code as well as of multiple letter codes had been involved here, a larger effect might well have been expected.

An implication of a word code account of these results that largely excludes letter code involvement is that word codes may not be dependent upon letter code output as their primary source of activation. Johnson (1975) has proposed that words are recognized by features that are independent of those responsible for letter recognition. If such a model were correct, then the question arises as to whether or not familiar words normally activate letter codes at all.

The word length effect found in both studies might be taken as evidence that some individual letter processing does occur. Other word matching studies have shown similar effects (e.g., Bruder, 1978; Eichelman, 1970). However, the magnitude of the word length effect in simultaneous matching tasks is sensitive to factors that cloud its interpretation. These include the visual angle of the display (see Bruder, 1978, vs. Eichelman, 1970) and familiarity of the word (Bruder, 1978, Experiment 3). Data from our laboratory have also indicated that larger word length effects are obtained when the words are presented one above the other, as in Bruder (1978) and Eichelman (1970), than when they are presented side by side, as in the experiments reported here. Because of these influences, understanding what the word length effect means in terms of individual letter processing is not entirely obvious. It could be argued that word length effects obtained from matching familiar words might well result from greater visual complexity of the 
longer patterns to be compared rather than an increase in the number of codes assessed during the comparison operation. It is also quite possible that both visual complexity and number of codes assessed contribute to the observed length effect. The data here do not allow us to distinguish between these influences.

If letter code activation does routinely occur when words are presented, then measuring it may require a situation that necessitates the individual processing of letters rather than one that allows a word to be processed holistically. Various kinds of degradation and spatial transformations have been shown to produce letter processing strategies. For example, Terry, Samuels, and LaBerge (1976) have shown that presenting mirror-imaged words requires subjects to process letter information directly. This was indicated by a steep rise in the word length function in the degraded mirror-imaged conditions relative to the flat function found for normally displayed words in the categorization task used.

In order to measure the effects of similarity under conditions promoting letter processing, we decided to use several kinds of spatial transformations. The matching task was now found to be no longer appropriate, since subjects could conceivably perform a matching operation on transformed words as though they were strings of unrelated letters without ever accessing word codes. Instead, we chose a lexical decision task, fashioned after that used by Meyer, Schvaneveldt, and Ruddy (1974). Here, a single cue item is displayed, followed by a single target item, and subjects are instructed to determine if the items are familiar English words. We will explore the identical, hi-similar, different, and neutral cue/target relationships previously used to measure how the latency of making a lexical decision about the target is influenced by the physical similarity of the prior cue item.

\section{EXPERIMENT 3}

In Experiment 3, the lexical decision task was first administered using normally displayed items to determine whether the cue/target relationships would yield results consistent with those of the matching studies. Specifically, we wanted to see if identical cue/target words produced facilitation and if similar cue/target words produced interference.

Meyer et al. (1974) had previously demonstrated that the lexical decision task was sensitive to both visual and phonological sources of similarity. When the cue and target shared all but the first letter and were phonemically dissimilar (COUCH-TOUCH), interference was observed. However, words that had different first letters and rhymed (BRIBE-TRIBE) showed some degree of facilitation.

Unfortunately, the interpretation of these findings is complicated by their dependence on the different cue/target condition comparisons only. It is possible that the facilitation of the rhyming pairs was due to expectancies rather than to phonemic relatedness per se. If so, then the phonemically dissimilar items may have produced interference. However, the lack of a neutral cue condition in these experiments makes it possible to evaluate the degree to which such strategic factors were involved.

For present purposes, we chose to ignore problems of phonemic similarity and to focus solely on visual perceptual similarity, as in the earlier studies. It should be noted that our rules for generating highly similar cue/target word pairs were such that rhymes did not occur. Here, cue/target items typically had some degree of phonemic similarity and dissimilarity (soupsoap). In general, the design of the study and the nature of the items were such as to be considered relatively insensitive to phonetic aspects of the cue/target words while allowing for visual similarity effects to emerge.

\section{Method}

Subjects. Forty native English-speaking college undergraduates participated in the experiment for two extra credit points in their introductory psychology course at the University of Minnesota.

Stimulus materials and design. Cue/target pairs were chosen from the matching materials used in Experiment 1 for identical, hi-similar, different, and neutral conditions. Neutral cues were always a single string of plus signs with an equivalent number of characters as the target word. There were four cue/target pairs at each of the three word lengths (four, five, and six letters) at each condition. An additional set of three-letter cue/target word pairs was generated using the selection criteria employed in Experiment 1 . Using a "rotated targets" design, target words were rotated across the four conditions and were paired with new cues to generate four sets of cue/target word pairs.

A single set of cue/target pairs was generated containing nonword targets. First, cue/target word pairs that bore the cue/target relationships to be tested were selected. Then the target was made into a pronounceable nonword by replacing one of its letters (bank-benk). Rules of normal English orthography were followed. There were two nonword items for each of the four word lengths in each cue/target condition.

The nonword items were added to each set of word target items to make four complete lists, each containing 96 items. There was a total of $64(67 \%)$ word-target items and $32(33 \%)$ nonword target items. Ten subjects were assigned randomly to each of the four stimulus lists. An additional set of practice materials was constructed containing 16 word target items and 16 nonword target items, with four items in each cue/target condition to be tested.

Procedure. Procedurally, the experiment followed the format of the others, with slight modifications in display and timing parameters due to the presentation of single word cue and target items. At the start of each trial, a cue item (either a word or a string of plus signs) was presented in the upper left quadrant of the screen. After 1,000 msec, the cue was removed, and the screen remained blank for the next $300 \mathrm{msec}$. Then, the target was presented in the lower right quadrant of the screen. The item remained on until the subject responded or for a maximum of $1,250 \mathrm{msec}$. Subjects were allowed up to $1,500 \mathrm{msec}$ to respond, as in the previous experiments. The ITI was $1,000 \mathrm{msec}$, during which time the screen remained blank.

Subjects were instructed to read the cue item in the upper part of the screen and then to shift their attention to the lower right corner, where the target would soon be presented. They were told to press the right button if the target was a familiar English word 


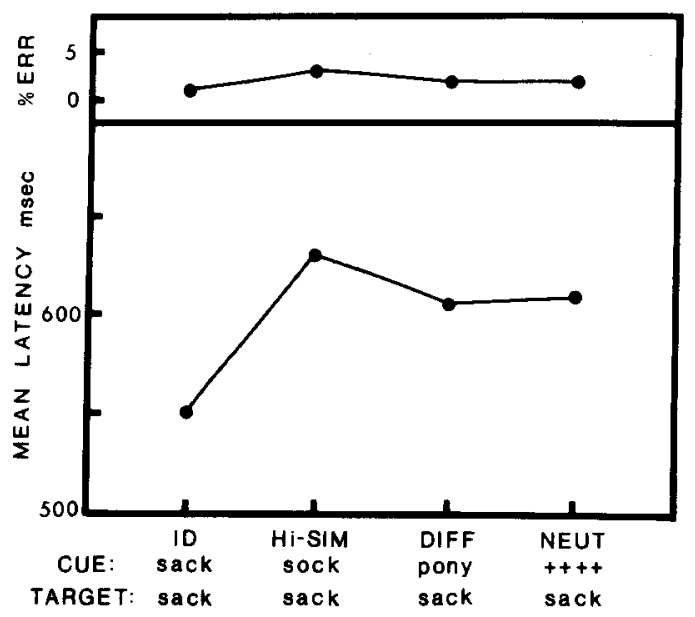

Figure 3. Mean response latency and percent errors in making lexical decisions as a function of cue/target similarity in Experiment 3.

and the left button if the target was not a word. No response decision was required with regard to the cue.

\section{Results}

Word target data (right-hand responses). The min $F^{\prime}$ analyses used here were similar to those used in Experiments 1 and 2. As before, the analyses of response latencies yielded a reliable condition effect [min $\left.F^{\prime}(3,287)=16.42, p<.001\right]$. As can be seen in Figure 3, the overall pattern of condition means resembles that observed in the matching experiments. The hi-similar interference effect observed here was reliable $[t(287)=-3.09, p<.01]$, although it was somewhat more modest than that previously observed. The facilitatory effect of the identical condition was also reliable $[\mathrm{t}(287)=7.79, \mathrm{p}<.001]$. There was also a small reliable word length effect [min $\left.F^{\prime}(3,95)=3.16, p<.05\right]$, with latencies increasing at approximately $13 \mathrm{msec}$ per letter. There was no reliable interaction between condition and length factors, and none of the factors analyzed were found to significantly influence error rates.

Nonword target data (left-hand responses). Nonword data were analyzed for condition effects, and no reliable effects were found for either latencies or error rates.

\section{EXPERIMENT 4}

The lexical decision task was sensitive to visual similarity relationships between the cue and target words in a manner like that evidenced in the matching task. Using normally presented words, identical facilitation and similarity interference were found. These effects were previously explained in terms of word code interactions.

In the next experiment, we wanted to determine whether evidence for letter code activation during cue presentation could be obtained. Here, we used spatially transformed targets to produce direct letter processing, thereby allowing us to measure prior letter code activity generated by the cue.

Four groups of subjects were first tested using normally displayed cue and target items. Then, in a second test, one group continued to receive normal displays, while each of the other groups received transformed displays. These transformations included: (1) reversed ordering of the letters, (2) reversed orientation or mirror-imaging of each letter, and (3) reversed orientation or mirror-imaging of the whole word as a unit. Figure 4 illustrates the target display for each of the groups. It can be seen that the reversed word manipulation represents the conjunction of the other two transformations.

It was hoped that one or more of these transformations would provide evidence for letter code activation by the development of facilitation in the similar cue/target condition.

\section{Method}

Subjects. Forty-eight native English-speaking college undergraduates in the introductory psychology course at the University of Minnesota received two extra credit points for their participation in this experiment.

Stimulus materials and design. More stringent stimulus selection criteria were imposed in this experiment to deal with certain problems encountered under transform manipulations. Many letters are physically unchanged by a mirror-image transformation. In lowercase, these include $i, 1, o, t, v, w$, and $x$. The inclusion of such "nonreversible" letters makes the reversed letter and reversed word transformations incomplete at an individual letter level of analysis. Hence, it was considered desirable to avoid using target items containing one or more of these letters. A further problem is that a reversed lowercase $b$ is visually identical to a nonreversed lowercase $d$ and vice versa. Target words containing these letters were omitted so as to avoid confusion regarding the identity of these letters. Since cue items were never transformed, no letter restrictions were observed in the selection of these items.

Because of the difficulty in obtaining sufficient target items to meet these criteria, a "fixed targets" design was used with three-, four-, and five-letter words only. There were two complete sets of test materials; each contained 48 words and 48 nonword targets. There were also eight items with nonword cues to be used as catch trials in which no overt response was required of the subject. Half

\begin{tabular}{|c|c|c|c|}
\hline Normal v & ord (Identical): & Reversed & Letters (Different) \\
\hline$\gg$ & arm $\gg$ & $\gg$ & lot $\gg$ \\
\hline$\gg$ & $\operatorname{arm} \gg$ & $\gg$ & esq $\gg$ \\
\hline
\end{tabular}

\begin{tabular}{|c|c|c|c|}
\hline Reversed & Order (similar): & Reversed & Word (Neutral \\
\hline$>>$ & fun & 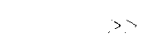 & $++t>>$ \\
\hline$<$ & naf & $\ll$ & $\forall a s<$ \\
\hline
\end{tabular}

Figure 4. Examples of cue/target displays for each group condition (bold print) in the second test of Experiment 4. As noted in parentheses, one of the cue/target relationships to be tested is shown for each group. Arrow brackets indicate the appropriate direction in which to read the word. 
of the nonword cues were paired with word targets, and half were paired with nonword targets. Additional items were also selected for practice items. The four cue/target conditions in Experiment 3 were presented here in both practice and test sets.

Procedure. The experimental session included a practice and test set under normal display conditions and a second practice and test under group transform conditions. Each practice contained 36 trials, and each test contained 104 trials. Data were analyzed for the test sets only.

The general trial format used in Experiment 3 was followed, with some minor modifications in the display and timing parameters. On each trial, a cue was presented in the upper center part of the screen for $1,000 \mathrm{msec}$. The screen then remained blank for $500 \mathrm{msec}$, following which time the target was presented in the lower center part of the screen. Due to the difficulty in recognizing the transformed words, the target remained on until the subject responded or for a maximum of $3,500 \mathrm{msec}$. Latencies exceeding 3,500 msec were considered misses. An error message followed incorrect responses and misses.

Cue displays were presented normally throughout the experiment. Targets were also displayed normally for all groups during the first practice and test sets. During the second practice and sets, the targets were displayed under the group conditions: (1) normal word, (2) reversed order of the letters, (3) reversed letter orientation, and (4) reversed word orientation. Subjects in the reversed order and reversed word groups were being asked to read the cue in a normal left-to-right direction and to read the target in the opposite direction. To reduce confusion about the direction in which to interpret any particular item, arrow brackets indicating the appropriate direction surrounded all cue and target items for all groups in both tests. The function of these brackets was explained to the subjects when the transformations were put into effect. Examples of cue/target displays are shown in Figure 4.

Unlike the previous experiment, subjects here were required to make a lexical decision on both cue and target items. When the cue was a nonword (catch trial), they were told to ignore the target and to wait for the next trial. When the cue was a word or a string of plus signs, the response assignments used in Experiment 3 were in effect.

Prior to the second practice, subjects were given additional instructions and were shown example cards illustrating the nature of the transformed targets they would be seeing. Subjects were informed that they had up to $31 / 2 \mathrm{sec}$ to respond. After the practice on the transform items, subjects were given feedback on their performance with respect to the number of errors and misses they had made.

\section{Results}

Test 1: Normal targets. Cue/target condition had a reliable effect on word target latencies [min $F^{\prime}(3,133)$ $=11.19, \mathrm{p}<.001$ ], yielding a pattern generally like that reported in Experiment 3. There were no overall group differences, and there was no evidence that condition or length effects varied across groups. As can be seen from the values in Table 2, identical target word latencies were reliably faster than those pro- duced by either the different or neutral conditions $[t(133)=3.99, p<.01$, and $t(133)=7.92$, $p<.01$, respectively]. Although the similar condition produced longer latencies than did the different condition $[t(133)=-2.90, p<.05]$, it yielded latencies that were somewhat faster than those from the neutral condition. The latter difference was not, however, statistically reliable. This deviation from previous experiments appears to be due to an increase in the neutral condition latencies, although, without further testing, it is difficult to know why this may have occurred. For present purposes, it is most important that the similar condition did not result in reliable facilitation relative to the controls.

The nonword values reported in Table 2 indicate that the latencies of the identical and similar conditions tended to be faster than those of the different and neutral conditions. There was, however, no overall significant effect of cue/target condition, and there were no other factors or interactions found to be statistically reliable in the analysis of nonword targets.

Test 2: Transformed targets. Word target data (right-hand responses) were as follows: As in Test 1, cue/target condition had a reliable effect on the response latencies for word targets in the second test $\left[\min F^{\prime}(3,120)=12.55, p<.001\right]$, as well as on their error rates $\left[\min F^{\prime}(3,127)=4.87, p<.01\right]$. The mean latencies and error rates for cue/target conditions in all four groups are provided in Table 3.

As illustrated in Figure 5, the effects of the cue/ target condition in the transformed groups was somewhat different from that obtained in the normal word group. Although the F values for the Group by Condition interaction were reliable for both the subjects analysis $[F(9,120)=3.29, \mathrm{p}<.01]$ and the item analysis $[F(9,216)=2.78, p<.01]$, the more conservative min $F^{\prime}$ value did not reach the standard level of significance $\left[\min F^{\prime}(9,321)=1.51\right.$, n.s.]. However, the effects of the similar and identical conditions relative to the combined neutral and different conditions were compared between the normal word groups and each of the other transform groups in a series of planned comparisons. There was a reliable difference between the effect of the similar condition in the normal word group and that obtained in the reversed letter group $[\mathrm{t}(321)=2.43, \mathrm{p}<.05]$ and the reversed word group $[t(321)=2.44, p<.05]$. As can be seen in

Table 2

Lexical Decision Data for Cue/Target Conditions in Normal Word Test 1 of Experiment 4

\begin{tabular}{|c|c|c|c|c|c|c|c|c|}
\hline \multirow[b]{3}{*}{ Target } & \multicolumn{8}{|c|}{ Cue/Target Condition } \\
\hline & \multicolumn{2}{|c|}{ Identical } & \multicolumn{2}{|c|}{ Similar } & \multicolumn{2}{|c|}{ Different } & \multicolumn{2}{|c|}{ Neutral } \\
\hline & Latency & Percent Errors & Latency & Percent Errors & Latency & Percent Errors & Latency & Percent Errors \\
\hline $\begin{array}{l}\text { Words } \\
\text { Nonwords }\end{array}$ & $\begin{array}{l}663 \\
947\end{array}$ & $\begin{array}{l}1.2 \\
5.7\end{array}$ & $\begin{array}{l}777 \\
901\end{array}$ & $\begin{array}{l}3.9 \\
4.7\end{array}$ & $\begin{array}{l}729 \\
978\end{array}$ & $\begin{array}{r}.6 \\
6.2\end{array}$ & $\begin{array}{l}794 \\
979\end{array}$ & $\begin{array}{l}3.8 \\
7.5\end{array}$ \\
\hline
\end{tabular}

Note-All latencies are reported in milliseconds. Data are collapsed across all four groups. 
Table 3

Lexical Decision Group Data for Word Targets in Transform Test 2 of Experiment 4

\begin{tabular}{|c|c|c|c|c|c|c|c|c|}
\hline \multirow[b]{3}{*}{ Group } & \multicolumn{8}{|c|}{ Cue-Target Condition } \\
\hline & \multicolumn{4}{|c|}{ Mean Latency (in Milliseconds) } & \multicolumn{4}{|c|}{ Mean Percent Errors } \\
\hline & Identical & Similar & Different & Neutral & Identical & Similar & Different & Neutral \\
\hline $\begin{array}{l}\text { Normal Word } \\
\text { Reversed Order } \\
\text { Reversed Letter } \\
\text { Reversed Word }\end{array}$ & $\begin{array}{r}575 \\
1366 \\
1547 \\
1177\end{array}$ & $\begin{array}{r}718 \\
1754 \\
1744 \\
1489\end{array}$ & $\begin{array}{r}673 \\
1885 \\
1847 \\
1631\end{array}$ & $\begin{array}{r}751 \\
1873 \\
1882 \\
1651\end{array}$ & $\begin{array}{l}1.3 \\
7.0 \\
4.8 \\
2.0\end{array}$ & $\begin{array}{r}7.9 \\
18.7 \\
17.3 \\
10.5\end{array}$ & $\begin{array}{r}3.4 \\
20.2 \\
24.8 \\
11.1\end{array}$ & $\begin{array}{r}7.6 \\
17.7 \\
16.5 \\
13.7\end{array}$ \\
\hline Mean & 1166 & 1426 & 1509 & 1539 & 3.8 & 13.6 & 14.9 & 13.9 \\
\hline
\end{tabular}

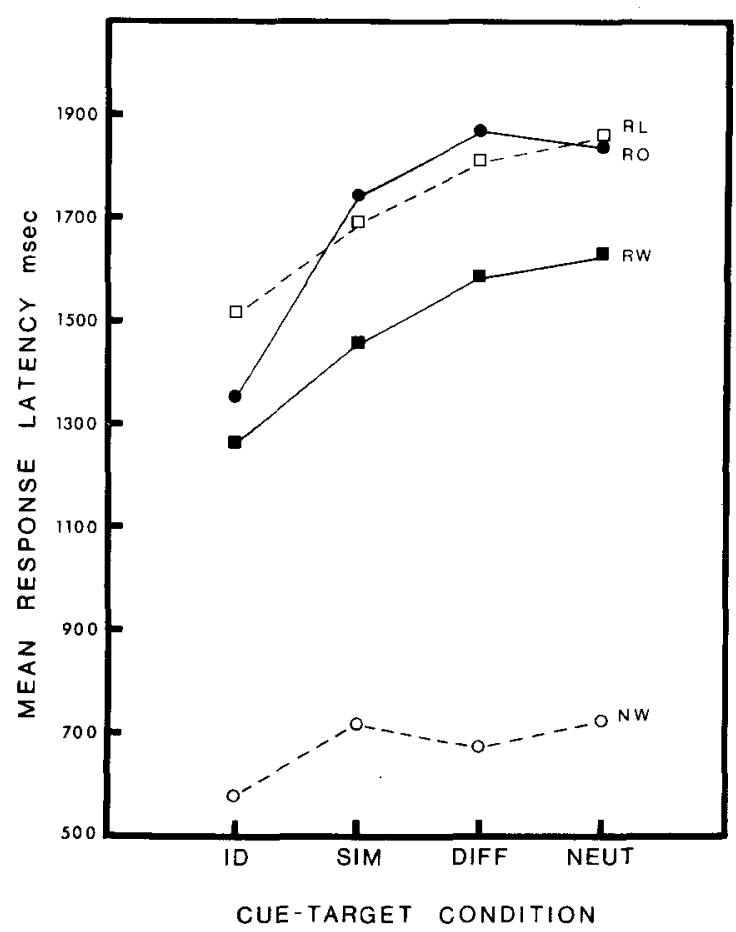

Figure 5. Mean latency to make lexical decisions on word targets as a function of cue/target visual similarity for normal word (NW), reversed order (RO), reversed letter (RL), and reversed word (RW) groups in Test 2 of Experiment 4.

Figure 5, both the reversed letter and the reversed word groups showed a decrease in reaction time relative to the neutral and different conditions, whereas the normal word group showed a slight increase in reaction time. Although the pattern of the reversed order group was similar to that of the other transform groups, the resulting interaction with the normal word group was not statistically reliable.

Identical targets produced facilitation in all the groups, but the magnitude of this effect was reliably greater in each of the transform groups, relative to the normal word groups [RO: $\mathrm{t}(321)=5.67, \mathrm{p}<.01$; RL: $\mathrm{t}(321)=3.01, \mathrm{p}<.01$; RW: $\mathrm{t}(321)=4.47, \mathrm{p}<.01]$.

As shown in Figure 6, there were large monotonic increases of as much as $\mathbf{2 0 0} \mathrm{msec}$ per letter as a function of word length in the transform groups, and this led to a reliable main effect $\left[\min F^{\prime}(2,121)=17.79\right.$, $\mathrm{p}<.001$ ]. In contrast, there was only a very modest effect of length in the normal word group, and this interaction between the transform and control groups and length was also reliable $\left[\min F^{\prime}(6,229)=3.28\right.$, $\mathrm{p}<.01]$.

There were also large group differences in both latencies [min $\left.F^{\prime}(3,49)=43.23, p<.001\right]$ and error rates $\left[\mathrm{min} \mathrm{F}^{\prime}(3,82)=4.65, \mathrm{p}<.01\right]$. Not surprisingly, all transform groups were slower and made more errors than did the normal word control group. Among the transform groups, the reversed word group produced reliably shorter latencies than either the reversed order group $[t(49)=2.86, p<.05]$ or the reversed letter group $[\mathrm{t}(49)=3.29, \mathrm{p}<.01]$.

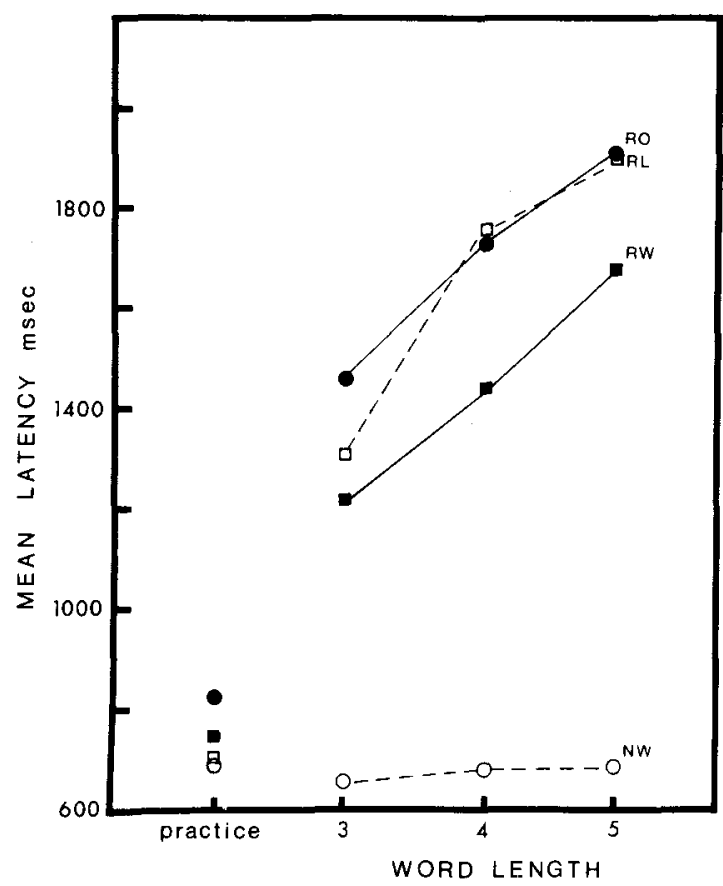

Figure 6. Mean latency to make lexical decisions as a function of the number of letters in the target word for normal word (NW), reversed order (RO), reversed letter (RL), and reversed word (RW) groups in Test 2 of Experiment 4. Practice data indicate group mean latencies collapsed across all word lengths for normally displayed words in Test 1. 
Table 4

Lexical Decision Group Data for Nonword Targets in Transform Test 2 of Experiment 4

\begin{tabular}{|c|c|c|c|c|c|c|c|c|}
\hline \multirow[b]{3}{*}{ Group } & \multicolumn{8}{|c|}{ Cue-Target Condition } \\
\hline & \multicolumn{4}{|c|}{ Mean Latency (in Milliseconds) } & \multicolumn{4}{|c|}{ Mean Percentage Errors } \\
\hline & Identical & Similar & Different & Neutral & Identical & Similar & Different & Neutral \\
\hline Normal Word & 823 & 800 & 912 & 911 & 3.4 & 2.7 & 14.5 & 6.3 \\
\hline Reversed Order & 1984 & 1924 & 2121 & 2186 & 3.4 & 7.0 & 7.3 & 9.7 \\
\hline Reversed Letter & 1962 & 2125 & 2275 & 2454 & 26.4 & 10.0 & 10.1 & 11.5 \\
\hline Reversed Word & 1762 & 1822 & 1928 & 2024 & 11.1 & 10.4 & 8.4 & 11.1 \\
\hline Mean & 1633 & 1668 & 1809 & 1894 & 11.1 & 7.5 & 10.1 & 9.7 \\
\hline
\end{tabular}

Nonword target data (left-hand responses). To a large extent, the nonword data reflect much the same pattern as did the word target data. Cue/target condition yielded a reliable main effect on nonword response latencies [min $\left.F^{\prime}(3,116)=6.25, \mathrm{p}<.001\right]$, as did word length $\left[\mathrm{min} \mathrm{F}^{\prime}(2,98)=24.22, \mathrm{p}<.001\right]$ and group treatment [min $\left.F^{\prime}(3,53)=57.19, p<.001\right]$. Group mean latencies and error rates are summarized for the nonword targets in Table 4.

As was true for word targets, both identical and similar conditions produced shorter latencies than did the different and neutral conditions. This was true for the normal word groups as well as for the transform groups.

The ordering of the groups was the same as that for word targets, although the only reliable difference among the transform groups was between the reversed word and reversed letter groups $[t(53)=$ $3.63, p<.01]$. Once again, length primarily affected only transform group latencies and not those of the normal word group, resulting in a reliable group by Length interaction $\left[\min F^{\prime}(6,292)=3.59, p<.01\right]$.

\section{Discussion}

The cue/target relationships produced markedly different effects in the transform and normal word groups. Identical cue/target word facilitated performance in all groups, but the magnitude of this effect was approximately three times greater in the transform groups, as is evident in Figure 5. When the cue and target words were highly similar, the normal word group continued to show no sign of facilitation and some slight degree of interference relative to when visually dissimilar target words were used. In contrast, all three transformation groups showed substantial facilitation to highly similar targets relative to both control cue/target conditions.

The facilitatory effects in the transform groups appear to measure letter code activity initiated by the normal presentation of the cue word. The greater magnitude of these effects relative to the normal word condition may be taken as evidence of multiple letter code activity. Alternatively, the larger facilitatory effects in the transform groups could indicate the operation of expectancies used by the subjects to help decode the spatially transformed targets. How- ever, there are two reasons that a dependence on such expectancies for repeated words and/or letters between the cue and target seems unlikely here. First, the different cue/target condition in the transform groups was no slower than the neutral condition, as would have been expected if strong expectancies were operating. Furthermore, identical and similar items together constituted only $50 \%$ of the total trials. Based on the findings of Posner and Snyder (1975), this may not be sufficient to encourage and maintain strong strategy effects.

The steep word length function in the transform groups is additional confirmation that subjects were forced to deal with spatially transformed words on a letter-by-letter basis. Note that the magnitude of the latency increases as a function of length for these transform groups is nearly four to five times greater than the 45- and 59-msec increases per letter found in the matching task. Indeed, the effects found here are more comparable to those of other studies in which direct letter processing is suspected to be dominant, as in the matching of mixed case word displays (Bruder, 1978 ) or the categorization of words in very young children (Samuels, LaBerge, \& Bremer, 1978).

The nonword data in this experiment also provided evidence for individual letter processing. The facilitation in both identical and similar conditions suggests that when an unfamiliar letter string is presented, some letter analysis occurs even when normal displays are provided. Bruder (1978) drew a similar conclusion based upon the greater word length effect in nonwords over words in a matching task.

An additional finding of interest is that the level of letter code activation in the transform groups does not appear to be influenced by the familiarity of the stimulus display. This is shown by the absence of a Cue/Target Condition by Group interaction among the transform groups. In other words, seeing a mirrorimaged letter can activate a letter code as well as can seeing a letter in its normal orientation. One suspects, however, that there may be differential time lags involved for the code to reach full activation under the two conditions, since perceptual familiarity typically has a pronounced effect on response time (e.g., Massaro, Jones, \& Lipscomb, 1978; Pollatsek, Well, Schindler, 1975; Terry, Samuels, \& LaBerge, 1976). 


\section{GENERAL DISCUSSION}

Overall, the pattern of data across all four experiments suggests that familiar words presented in normally oriented typography may activate word codes without depending upon letter code activation. This is not to say, however, that letter code activation does not take place under normal display conditions. The facilitatory results in the transform groups in Experiment 4 clearly indicate that letter codes are being activated by the normal cue presentation.

Perhaps letter and word codes are typically two different endpoints in the processing of written language rather than being different levels in the same hierarchically structured analyzing system. Such an argument has been raised by Johnson (1975), and recent support for the independence of letter and word perception has been reported by O'Hara (1980). He found that positioning unrelated letters between two letters to be matched slows down the response, but such interference is greatly reduced or even eliminated when the interpolated letters make up a familiar word. These data clearly show that letters in a word do not interact with the two target letters as they do when presented in a random order.

A question remains as to whether the letter and word codes are activated by the same information or different information in the display. Johnson (1975) has postulated that letter and word recognition are likely to depend upon quite different sets of features, but he does not specify what these different sets might include. The ordering of the transform groups in Experiment 4 provides some evidence that words are not recognized simply from the composite information derived from the bits and pieces of lines and curves that make up the letters. Here, the reversed word transformation was found to result in less impairment than either of the other transforms, even though mirror imaging involves both reversed ordering of the letters and reversed orientation of the letters! One kind of information that may be better preserved in the reversed words relative to the others consists of the relationships between letters or letter features. While features within letters have certain set relationships that are important for letter recognition, features between letters have certain set relationships that may be important for word recognition, particularly for purposes of correctly ordering the elements. This source of information may also underlie our sensitivity to orthographic regularity.

The role of interletter relations has been indicated in those studies, using mixed case displays (e.g., Bruder, 1978; McClelland, 1976; Smith, 1969), and in a study comparing the acquisition of new words written in script vs. uppercase type (McClelland, 1977). The use of such relatively "global" kinds of information in word processing probably increases developmentally. This has been partly suggested by the differential sensitivity of adults and children to mixed case manipulations (Spragins, Lefton, \& Fisher, 1976). Adults were shown to be relatively more impaired by the distortion of normal interletter relationships than were either third- or fifth-grade students. It may be the use of such interletter or whole word pattern information that allows word code activation to be independent of letter code activation, as indicated in the present findings as well as those of O'Hara (1980).

\section{REFERENCES}

Bruder, G. A. Role of visual familiarity in the word-superiority effects obtained with the simultaneous-matching task. Journal of Experimental Psychology: Human Perception and Performance, 1978, 4, 88-100.

Carroll, J. B., Davis, P., \& Richman, B. Word frequency book. New York: American Heritage, 1971.

Clark, H. H. The language-as-fixed-effect fallacy: A critique of language statistics in psychological research. Journal of Verbal Learning and Verbal Behavior, 1973, 12, 335-359.

Eichelman, W. H. Familiarity effects in the simultaneous matching task. Journal of Experimental Psychology, 1970, 86, 275282.

Eriksen, B. A., \& Eriksen, C. W. The importance of being first: A tachistoscopic study of the contribution of each letter to the recognition of four-letter words. Perception \& Psychophysics, 1974, 15, 66-72.

Estes, W. K. On the interaction of perception and memory in reading. In D. LaBerge \& S. J. Samuels (Eds.), Basic processes in reading: Perception and comprehension. Hillsdale, N.J: Erlbaum, 1977.

Johnson, N. F. On the function of letters in word identification: Some data and a preliminary model. Journal of Verbal Learning and Verbal Behavior, 1975, 14, 17-29.

LABERGE, D. Identification of two components of the time to switch attention: $A$ test of a serial and a parallel model of attention. In S. Kornblum (Ed.), Attention and performance IV. New York: Academic Press, 1973.

LABerge, D., \& SAmuels, S. J. Toward a theory of automatic information processing in reading. Cognitive Psychology, 1974, 6, 292-323.

Massaro, D. W. Preliminary and secondary recognition in reading. In D. W. Massaro (Ed.), Understanding language: $A n$ information processing analysis of speech perception, reading, and psycholinguistics. New York: Academic Press, 1975.

Massaro, D. W., Jones, R. D., \& Lipscomb, C. Role of prior knowledge on naming and lexical decisions with good and poor stimulus information. Journal of Experimental Psychology: Human Learning and Memory, 1978, 4, 498-512.

MCClelland, J. L. Preliminary letter identification in the perception of words and nonwords. Journal of Experimental Psychology: Human Perception and Performance, 1976, 2, 80-91.

McClelland, J. L. Letter and configural information in word identification. Journal of Verbal Learning and Verbal Behavior, 1977, 16, 137-150.

McClelland, J. L. On the time relations of mental processes: An examination of systems of processes in cascade. Psychological Review, 1979, 86, 287-330.

Meyer, D. E., Schvaneveldt, R. W., \& Ruddy, M. G. Functions of graphemic and phonemic codes in visual word-recognition. Memory \& Cognition, 1974, 2, 309-321.

O'Hara, W. P. Evidence in support of word unitization. Perception \& Psychophysics, 1980, 27, 390-402. 
Pollatsex, A., Well, A. D., \& Schindler, R. M. Familiarity affects visual processing of words. Journal of Experimental Psychology: Human Perception and Performance, 1975, 1, 328-338.

Posner, M. I. Chronometric explorations of mind. Hillsdale, N.J: Erlbaum, 1978.

Posner, M. I., \& Snyder, C. R. R. Facilitation and inhibition in the processing of signals. In P. M. A. Rabbitt \& S. Dornic (Eds.), Attention and performance $V$. New York: Academic Press, 1975.

Rayner, K., \& Posnansky, C. Stages of processing in word identification. Journal of Experimental Psychology: General, 1978, 107, 64-80.

Samuels, S. J., LaBerge, D., \& Bremer, C. D. Units of word recognition: Evidence for developmental changes. Journal of Verbal Learning and Verbal Behavior, 1978, 17, 715-720.

SMITH, F. Familiarity of configuration vs. discriminability of features in the visual identification of words. Psychonomic Science, 1969, 14, 261-263.

Spragins, A. B., Lefton, L. A., \& Fisher, D. F. Eye movements while reading spatially transformed text: A developmental study. Memory \& Cognition, 1976, 4, 36-42.

Terry, P., Samuels, S. J., \& LaBerge, D. The effects of letter degradation and letter spacing on word recognition. Journal of Verbal Learning and Verbal Behavior, 1976, 15, 577-585.

(Received for publication December 18, 1980; revision accepted April 14, 1981.) 